Article

\title{
An Assessment of the Level of COVID-19 Anxiety among Pregnant Women in Poland: A Cross-Sectional Study
}

\author{
Kinga Janik $^{1, *}$, Urszula Cwalina ${ }^{2}(D)$, Grażyna Iwanowicz-Palus ${ }^{3}\left(\mathbb{D}\right.$ and Mateusz Cybulski $^{1}$ \\ 1 Department of Integrated Medical Care, Faculty of Health Sciences, Medical University of Białystok, \\ M. Skłodowskiej-Curie 7A Str., 15-096 Białystok, Poland; mateusz.cybulski@umb.edu.pl \\ 2 Department of Statistics and Medical Informatics, Faculty of Health Sciences, Medical University of Białystok, \\ Szpitalna 37 Str., 15-295 Białystok, Poland; urszula.cwalina@umb.edu.pl \\ 3 Department of Development in Midwifery, Faculty of Health Sciences, Medical University of Lublin, \\ Staszica 4/6 Str., 20-081 Lublin, Poland; spupalus@umlub.pl \\ * Correspondence: kinga.janik@umb.edu.pl; Tel.: +48-(85)-748-55-28
}

Citation: Janik, K.; Cwalina, U.; Iwanowicz-Palus, G.; Cybulski, M. An Assessment of the Level of COVID-19 Anxiety among Pregnant Women in Poland: A Cross-Sectional Study. J. Clin. Med. 2021, 10, 5869 . https://doi.org/10.3390/jcm10245869

Academic Editors: Michele Roccella and Elena Tomba

Received: 8 October 2021

Accepted: 13 December 2021

Published: 14 December 2021

Publisher's Note: MDPI stays neutral with regard to jurisdictional claims in published maps and institutional affiliations.

Copyright: (c) 2021 by the authors. Licensee MDPI, Basel, Switzerland. This article is an open access article distributed under the terms and conditions of the Creative Commons Attribution (CC BY) license (https:// creativecommons.org/licenses/by/ $4.0 /)$.

\begin{abstract}
Introduction: The COVID-19 pandemic has caused general anxiety worldwide. Pregnant women are at a much higher risk of developing the infection due to multiple changes that occur in the body during this period. The consequences of the disease can be dramatic not only for the expectant mothers, but also for their unborn children. SARS-CoV-2 infection is generally known to cause serious concerns about future health and life. The data on the severity of COVID-19 pandemicrelated anxiety in pregnant women are insufficient. The aim of the study was to assess the level of COVID-19-related anxiety among pregnant women in Poland. Materials and Methods: The study included 173 pregnant women who volunteered for the research. The research was conducted by means of an online diagnostic survey containing an original questionnaire and the following standardized tools: State-Trait Anxiety Inventory (STAI), Short Health Anxiety Inventory (SHAI), and General Anxiety Disorder-7 (GAD-7). Results: Women hospitalised during pregnancy differed statistically significantly in terms of STAI-X1 scores. Primiparas obtained statistically significantly higher SHAI scores than multiparas. Women with higher education had higher SHAI scores. In the GAD-7 scale, $13.3 \%$ of respondents obtained a score suggesting a suspected generalised anxiety disorder. Conclusions: Pregnant women are concerned about both developing COVID-19 and the consequences of infection for themselves and their unborn children. The study demonstrated anxiety of varying severity (depending on the tool used). Hospital stay during pregnancy is an additional stressor in expectant women. Further studies are needed to assess the level of COVID-19-related anxiety to assess this phenomenon in Poland in more detail.
\end{abstract}

Keywords: anxiety; COVID-19; fear; general anxiety disorder-7 (GAD-7); pregnant; SARS-CoV-2; short health anxiety inventory (SHAI); state-trait anxiety inventory (STAI)

\section{Introduction}

The current COVID-19 pandemic is considered to be an example of a natural disaster with such a heavy global health burden, from which more than 236 million people worldwide are suffering and almost 5 million people have died [1]. Poland ranks 16th among the countries with the highest number of coronavirus cases in the world, with 2,918,863 people infected and 75,834 deaths [2].

The COVID-19 pandemic has caused panic and mental health problems around the world [3]. Frequent preventive measures (e.g., washing hands, masking, social distancing, and isolation) during a pandemic obsess people, which increases the risk of psychological damage [4]. Moreover, the pandemic has caused changes in everyday life, which has increased the risk of anxiety and depression [5].

Pregnant women are more vulnerable to any effects of the COVID-19 crisis, which requires action to protect this population [6]. During a pandemic, pregnant women have 
limited access to primary health care services [7]. Additional factors affecting their mental health are concerns about exposure to COVID-19 and concerns about COVID-19 vaccinations [8]. The prevalence of mental disorders in pregnant women was much higher during the COVID-19 pandemic than in the pre-pandemic period [9,10]. Fear of COVID-19, anxiety, and depression were the most common mental disorders among pregnant women [11,12]. Such disorders were associated with adverse effects of pregnancy, such as preterm labor, low for gestational age, and low birth weight of the newborn [13,14].

While COVID-19 is well-known to cause considerable fear among the general population, there is a little data on the perceived anxiety related to the ongoing COVID-19 pandemic in Poland, particularly among pregnant women. Therefore, the aim of the study was to analyse and assess the symptoms of COVID-19-related anxiety among pregnant women; in particular, to evaluate trait and state anxiety along with health anxiety and generalized anxiety disorder. Additionally, we assessed the impact of selected variables on the severity of anxiety symptoms in the study group. We assumed that the severity of anxiety disorders among pregnant women in Poland would be moderate.

\section{Materials and Methods}

\subsection{Study Design and Data Collection}

The study was conducted from 5 April 2021 to 26 July 2021. The study group included volunteers. Women at various stages of pregnancy were included in the study. We placed a link to the questionnaire, created with the use of a dedicated software (Webankieta) (Get Feedback, Warsaw, Poland) on social media. There were six discussion groups for pregnant women, which gathered 373 women in total. The respondents' responses were recorded on the platform used and then downloaded as raw data for statistical analysis. The mean time to complete the questionnaire was $23 \mathrm{~min}$.

In addition to female gender and pregnancy, written informed consent was an additional inclusion criterion. Participation in the anonymous study was voluntary. Each participant could withdraw from the study at any time.

There were 589 views on the platform. Considering the number of views, the level of completing the entire questionnaire was $29.33 \%$. A total of 19 questionnaires were not fully completed.

\subsection{Measures}

We used our own questionnaire dedicated for this study. It contained sociodemographic questions and a set of 24 closed questions on the stressors associated with the current epidemiological situation due to SARS-CoV-2 coronavirus infections. Furthermore, we used the following standardised tools: General Anxiety Disorder-7 (GAD-7), Short Health Anxiety Inventory (SHAI), and State-Trait Anxiety Inventory (STAI).

\subsubsection{State-Trait Anxiety Inventory (STAI)}

The STAI scale is built of two independent subsections. Each part includes 20 items. The first part, STAI X-1, evaluates anxiety as an emotional state at the moment. The second part, STAI X-2, assesses anxiety as a personality trait [15]. The respondent chooses one of the 4 statements for each item. The sum of all the answers for each individuals determines the overall level of anxiety. The score for each subsection is between 20 and 80 points. The higher the total score, the higher the level of anxiety experienced. Suspicion of an anxiety disorders occurs when the sum of the points is 39-40 [16,17].

\subsubsection{Short Health Anxiety Inventory (SHAI)}

The Short Health Anxiety Inventory (SHAI) is a scale that consists of 18 items and is used to assess anxiety in two aspects: probability of the disease and the negative effects of the disease. Each of the 18 statements contains four options. Respondents choose the one that best describes their emotions over the past 6 months. 
The responses are rated on a 4-point Likert scale, where: 0 indicates lack of symptoms, 1 -mild symptoms, 2 -severe symptoms, and 3 -very severe symptoms. The cut-off point for detecting health anxiety is 20 points $[18,19]$.

\subsubsection{Generalised Anxiety Disorder Assessment (GAD-7)}

The GAD-7 is a seven-point scale that is used to assess the level of anxiety and to assess the risk of developing generalized anxiety disorder (GAD). The questions included in the questionnaire concern the subjective assessment of anxiety, tension, nervousness, the ability to control emotions, the ease of their manifestation, and problems with relaxation The responses are rated on a 3-point Likert scale, where: 0 indicates not at all, 1 -several days, 2-more than half the days, and 3-nearly every day. The assessment is based on the past 2 weeks. Scores 5, 10, and 15 are mild, moderate, and severe, respectively. Generalized anxiety disorder is likely if the sum of the points is at least 10 [20].

\subsection{Procedure and Ethical Considerations}

The study was conducted in accordance with the recommendations, and was reviewed and approved by the Ethics Committee of the Medical University of Bialystok (No. APK.002.248.2021). All participants gave a written informed consent in accordance with the Declaration of Helsinki.

\subsection{Statistical Analysis}

Statistica 13.3 (StatSoft Company, Hamburg, Germany) was used for statistical analysis. The analysed variables were of dichotomous, interval, or ordinal nature. The chi-square test was used for dichotomous variables, and basic descriptive statistics for interval results. We used the Mann-Whitney $U$ test to determine statistical significance. The level of statistical significance was set at $p<0.05$ for each test.

\section{Results}

A total of 173 women participated in the study, which accounted for $49 \%$ of women who completed the questionnaire. Detailed sociodemographic characteristics of study participants are presented in Table 1.

The respondents were asked if they were concerned about contracting COVID-19 during pregnancy. It was found that infection with COVID-19 during pregnancy had a significant impact on the answer to this question. Fear of contracting COVID-19 was reported by $30.77 \%$ of women with a history of infection and over $50 \%$ of women in the group with no such history.

Table 2 summarizes the descriptive statistics of the standardised tools used in the study. A detailed analysis of GAD-7 results showed that the total score indicated anxiety symptoms of varying severity in $71 \%$ of respondents. A total of $23(13.3 \%)$ respondents scored at least 10 points, which suggests a suspected generalised anxiety disorder. The mean score obtained by respondents was 13.29 for the SHAI scale. In the GAD-7 scale, most respondents scored between 5 and 9 points. The mean scores obtained in STAI-XI and STAI-X2 were similar, i.e., 42.26 and 40.24, respectively. Details are shown in Table 2. 
Table 1. Sociodemographic characteristics of respondents.

\begin{tabular}{|c|c|c|c|}
\hline \multicolumn{2}{|c|}{ Sociodemographic Feature } & \multirow{2}{*}{$\begin{array}{c}n \\
15\end{array}$} & \multirow{2}{*}{$\begin{array}{c}\% \% \\
8.67 \%\end{array}$} \\
\hline & $<25$ & & \\
\hline Age (years) & $25-34$ & 132 & $76.30 \%$ \\
\hline & $\geq 35$ & 26 & $15.03 \%$ \\
\hline \multirow{4}{*}{ Education } & middle school & 1 & $0.58 \%$ \\
\hline & basic vocational & 13 & $7.51 \%$ \\
\hline & secondary & 46 & $26.59 \%$ \\
\hline & higher & 113 & $65.32 \%$ \\
\hline \multirow{4}{*}{ Marital status } & married & 150 & $86.70 \%$ \\
\hline & divorced & 3 & $1.73 \%$ \\
\hline & single & 15 & $8.67 \%$ \\
\hline & unmarried relationship & 5 & $2.89 \%$ \\
\hline \multirow{2}{*}{ Place of residence } & urban & 139 & $80.35 \%$ \\
\hline & rural & 34 & $19.65 \%$ \\
\hline \multirow{4}{*}{ Socioeconomic status } & very good & 39 & $22.54 \%$ \\
\hline & good & 111 & $64.16 \%$ \\
\hline & moderate & 23 & $13.30 \%$ \\
\hline & poor & 0 & $0.00 \%$ \\
\hline \multirow{6}{*}{ Number of children } & 0 & 83 & $47.98 \%$ \\
\hline & 1 & 65 & $37.57 \%$ \\
\hline & 2 & 17 & $9.83 \%$ \\
\hline & 3 & 6 & $3.47 \%$ \\
\hline & 4 & 1 & $0.58 \%$ \\
\hline & 5 & 1 & $0.58 \%$ \\
\hline \multirow{2}{*}{ Parity } & primipara & 83 & $47.98 \%$ \\
\hline & multipara & 90 & $52.02 \%$ \\
\hline \multirow{3}{*}{ Trimester } & I (1-13 weeks) & 16 & $9.25 \%$ \\
\hline & II (14-26 weeks) & 25 & $14.45 \%$ \\
\hline & III (27-40 weeks) & 132 & $76.30 \%$ \\
\hline \multirow{2}{*}{ History of mental disorders } & yes & 9 & $5.20 \%$ \\
\hline & no & 164 & $94.80 \%$ \\
\hline \multirow{2}{*}{$\begin{array}{c}\text { History of psychotropic } \\
\text { therapy }\end{array}$} & yes & 10 & $5.78 \%$ \\
\hline & no & 163 & $94.22 \%$ \\
\hline \multirow{2}{*}{$\begin{array}{l}\text { History of the prevalence of } \\
\text { COVID-19 }\end{array}$} & yes & 26 & $15.03 \%$ \\
\hline & no & 147 & $84.97 \%$ \\
\hline
\end{tabular}

Table 2. Summary of descriptive statistics of the standardised research tools.

\begin{tabular}{cccccccc}
\hline & $\mathbf{M}$ & SD & $\mathbf{Q}_{\mathbf{1}}$ & $\mathbf{M e}$ & $\mathbf{Q}_{\mathbf{3}}$ & $\mathbf{M i n}$. & Max. \\
\hline SHAI & 13.29 & 6.17 & 9 & 13 & 17 & 2 & 40 \\
GAD-7 & 5.79 & 3.90 & 3 & 5 & 7 & 0 & 21 \\
STAI-X1 & 42.26 & 11.20 & 34 & 41 & 50 & 22 & 74 \\
STAI-X2 & 40.25 & 8.50 & 34 & 40 & 45 & 23 & 69 \\
\hline
\end{tabular}

Abbreviations: GAD-7-General Anxiety Disorder-7, M-mean, Max.-maximum, Me-median, Min.-minimum, SD—standard deviation, SHAI-Short Health Anxiety Inventory, STAI-State-Trait Anxiety Inventory, $\mathrm{Q}_{1}$-lower quartile, and $\mathrm{Q}_{3}$ - upper quartile.

Primiparas were found to have statistically significantly $(p=0.031)$ higher SHAI scores $(\mathrm{M}=14.45, \mathrm{Me}=14)$ compared to multiparas $(\mathrm{M}=12.22, \mathrm{Me}=12)$. Primiparas were significantly younger. Both study groups were also compared for the following scales: GAD-7 and both STAI subscales. No statistically significant differences were found for these tools (Table 3). 
Table 3. Comparison of primiparas and multiparas for SHAI, GAD-7, and STAI.

\begin{tabular}{|c|c|c|c|c|c|c|c|c|c|c|c|}
\hline \multirow{2}{*}{ Tools } & \multicolumn{5}{|c|}{ Primiparas $(n=83)$} & \multicolumn{5}{|c|}{ Multiparas $(n=90)$} & \multirow{2}{*}{$p$} \\
\hline & $\mathbf{M}$ & SD & $\mathbf{Q}_{1}$ & Me & $\mathbf{Q}_{3}$ & $\mathbf{M}$ & SD & $\mathrm{Q}_{1}$ & Me & $\mathrm{Q}_{3}$ & \\
\hline SHAI & 14.45 & 6.81 & 10 & 14 & 18 & 12.22 & 5.35 & 9 & 12 & 16 & 0.031 \\
\hline GAD-7 & 6.45 & 4.27 & 4 & 6 & 8 & 5.19 & 3.43 & 3 & 5 & 7 & 0.066 \\
\hline STAI-X1 & 43.49 & 12.01 & 35 & 41 & 53 & 41.12 & 10.33 & 33 & 41 & 47 & 0.218 \\
\hline STAI-X2 & 40.35 & 8.24 & 34 & 41 & 46 & 40.16 & 8.78 & 34 & 40 & 44 & 0.753 \\
\hline
\end{tabular}

Abbreviations: GAD-7—General Anxiety Disorder-7, M-mean, Me—median, $p-p$-value, SD—standard deviation, SHAI—Short Health Anxiety Inventory, STAI-State-Trait Anxiety Inventory, $\mathrm{Q}_{1}$-lower quartile, and $\mathrm{Q}_{3}$ - upper quartile.

The analysis has shown that women with higher education scored statistically significantly higher in SHAI ( $p=0.019, \mathrm{M}=14.17, \mathrm{Me}=13)$ and GAD-7 $(p=0.006, \mathrm{M}=6.31$, $\mathrm{Me}=6$ ). No statistically significant results were found for the other scales (Table 4 ).

Table 4. Comparison of women with and without higher education for the following tools: SHAI, GAD-7, and STAI.

\begin{tabular}{|c|c|c|c|c|c|c|c|c|c|c|c|}
\hline \multirow{2}{*}{ Tools } & \multicolumn{5}{|c|}{$\begin{array}{l}\text { Higher Education } \\
\qquad(n=113)\end{array}$} & \multicolumn{5}{|c|}{$\begin{array}{l}\text { No Higher Education } \\
\qquad(n=60)\end{array}$} & \multirow{2}{*}{$p$} \\
\hline & $\mathbf{M}$ & SD & $\mathrm{Q}_{1}$ & $\mathrm{Me}$ & $\mathrm{Q}_{3}$ & $\mathbf{M}$ & SD & $\mathrm{Q}_{1}$ & $\mathrm{Me}$ & $\mathrm{Q}_{3}$ & \\
\hline SHAI & 14.17 & 6.15 & 10 & 13 & 18 & 11.63 & 5.93 & 7.5 & 12 & 15.5 & 0.019 * \\
\hline GAD-7 & 6.31 & 3.96 & 4 & 6 & 8 & 4.82 & 3.62 & 2 & 4 & 7 & 0.006 * \\
\hline STAI-X1 & 41.87 & 11.19 & 34 & 40 & 48 & 43 & 11.27 & 37 & 41 & 52 & 0.369 \\
\hline STAI-X2 & 40.21 & 8.75 & 33 & 40 & 44 & 40.32 & 8.08 & 35.5 & 40 & 45.5 & 0.777 \\
\hline
\end{tabular}

Abbreviations: GAD-7—General Anxiety Disorder-7, M-mean, Me—median, $p$ - -value, SD—standard deviation, SHAI—Short Health Anxiety Inventory, STAI—State-Trait Anxiety Inventory, $Q_{1}$-lower quartile, $Q_{3}$ —upper quartile, and * —statistically significant.

Hospitalised pregnant women scored significantly higher in STAI-X1. No statistically significant differences were found between pregnant women hospitalised during pregnancy and those not requiring hospitalisation in the remaining scales (Table 5).

Table 5. The impact of hospital stays during pregnancy on the rating of anxiety.

\begin{tabular}{|c|c|c|c|c|c|c|c|c|c|c|c|}
\hline \multirow[t]{2}{*}{ Tools } & \multicolumn{5}{|c|}{$\begin{array}{l}\text { Hospitalised during Pregnancy } \\
\qquad(n=93)\end{array}$} & \multicolumn{5}{|c|}{$\begin{array}{l}\text { Not Hospitalised } \\
\text { during Pregnancy } \\
\quad(n=80)\end{array}$} & \multirow[t]{2}{*}{$p$} \\
\hline & $\mathbf{M}$ & SD & $\mathrm{Q}_{1}$ & Me & $\mathrm{Q}_{3}$ & $\mathbf{M}$ & SD & $\mathrm{Q}_{1}$ & Me & $\mathrm{Q}_{3}$ & \\
\hline SHAI & 12.77 & 5.52 & 10 & 12 & 15 & 13.88 & 6.84 & 8.5 & 13.5 & 18 & 0.215 \\
\hline GAD-7 & 5.76 & 3.91 & 3 & 6 & 7 & 5.82 & 3.90 & 3 & 5 & 7 & 0.951 \\
\hline STAI-X1 & 44.14 & 11.55 & 37 & 41 & 52 & 40.07 & 10.42 & 32 & 39 & 46.5 & 0.019 * \\
\hline STAI-X2 & 39.55 & 8.02 & 34 & 40 & 44 & 41.06 & 9.01 & 34.5 & 40 & 45 & 0.459 \\
\hline
\end{tabular}

Abbreviations: GAD-7—General Anxiety Disorder-7, M-mean, Me—-median, $p$ - -value, SD—standard deviation, SHAI—Short Health Anxiety Inventory, STAI—State-Trait Anxiety Inventory, $Q_{1}$ - lower quartile, $Q_{3}$ - upper quartile, and * - statistically significant.

\section{Discussion}

So far, it has been established that the outbreak of the pandemic increased the level of mental health disorders in the general population [21,22], and it is more visible in women than in men. Some studies report that during catastrophes or major events, pregnant women are more likely to develop mental health problems than in the general population [23,24]. A recent systematic review and meta-analysis [25] assessing the impact of the pandemic on the mental health of pregnant women has shown that the level of mental health disorders in pregnant women is $37 \%$. Our study showed that women who had 
COVID-19 had lower levels of fear of infection with the SARS-CoV-2 than pregnant women who had not contracted the disease so far. Different results were obtained in another Polish study by Nowak et al. [26]. The authors proved that pregnant women who had been infected with SARS-CoV-2 experienced a higher level of anxiety than those who had not been infected so far.

Our study showed moderate anxiety among pregnant women in the STAI scale. Another study among pregnant women also assessed the level of antenatal anxiety using the STAI scale. Similar findings were obtained in both studies [27]. Similar results in the same scale were also shown in a study in Italy [28]. These findings confirm the conclusions obtained by Sinjari et al. [29], that questionnaires could be useful tools to assess patients conditions before the visit to a doctor.

Considering the parity of respondents, we found that primiparas show higher COVID19-related anxiety than multiparous women, as confirmed by SHAI scores. STAI results reported by Italian researchers also confirmed our hypothesis [28]. Such findings may be due to both the new life situation and the lack of knowledge about pregnancy and coronavirus infection during this special time.

The data on the impact of gestational age on the level of COVID-19-related anxiety among pregnant women are contradictory. In our analysis, we compared the scores obtained in the standardized scales depending on the trimester of pregnancy, but no statistically significant differences were found. Other authors reported higher STAI scores in the first and third trimesters than those obtained in our study [30]. Schubert et al. showed that, on the other hand, STAI scores remained stable throughout pregnancy [31].

We measured the prevalence of anxiety symptoms using the GAD-7 scale. It was found to be high, i.e., $62.5 \%$ among pregnant women, including $49 \%$ with mild, $10 \%$ with moderately severe, and 3.5\% with severe anxiety due to COVID-19. Other studies have also shown that pregnant women are much more prone to stress during the COVID-19 pandemic [32].

Our analysis showed that pregnant women with higher education were significantly older and scored statistically significantly higher in both SHAI and GAD-7. Similar findings on the impact of higher education on the increased levels of anxiety have been reported by other authors [32]. It can be assumed that greater awareness of one's own health negatively affects its loss as a result of a serious illness. The differences in the obtained results can be due to the dynamic nature of the disease and the fact that it is perceived differently around the world.

In this study, the median STAI score for anxiety was 41 . A total of $57.23 \%$ of the pregnant women scored $\geq 40$. In a similar study involving pregnant women, the median score in the same scale was 37, including a score of $\geq 40$ in $38.2 \%$ of participants [33]. Another study among pregnant women showed that the overall prevalence of anxiety symptoms measured with STAI (STAI > 40) was 62.6\% [34]. An Italian study found similar levels of COVID-19-related anxiety in pregnant women (68\%) [30]. Turkish studies also reported STAI scores above the cut-off for clinically significant symptoms of anxiety [35]. Similar findings in all the above-mentioned studies may be due to the different state of the women (pregnancy) and their concern about the health of their unborn children.

The presented results confirm COVID-19-related anxiety among pregnant women. Its level varies and is related to sociodemographic factors. Due to the negative effects of anxiety and stress on pregnant women and their unborn children, further research is needed on anxiety caused by the COVID-19 pandemic to prevent negative effects and improve the health of the population. Mental health screening for pregnant women should be included in the mandatory prenatal screening to reduce any potential anxiety symptoms.

\section{Limitations of the Study}

The study has certain limitations. The presented results come from an analysis based on a subjective assessment of anxiety symptoms in pregnant women. Although we used scales that are considered sensitive research tools, they are based on subjective feelings 
and do not include objective criteria of clinical symptoms, which may lead to false-positive results. The number of pregnant women participating in the study is another limitation. The small sample size does not allow for extrapolation of results to the general population of pregnant women in Poland. However, despite these limitations, our findings can be a reference point for further studies assessing the level of COVID-19-related anxiety among pregnant women both in Poland and in the world.

\section{Conclusions}

In conclusions, primiparas showed statistically significantly higher anxiety levels than multiparas. Higher education also contributed to higher scores. Hospital stays during pregnancy contributed to statistically higher STAI-X1 scores. There was no statistically significant relationship between pregnancy trimester and the prevalence of COVID-19. There is a need to continue research on COVID-19-related anxiety among pregnant women in Poland to assess this phenomenon and the causative factors in more detail.

The COVID-19 pandemic has serious consequences. Therefore, in the periods of health crisis, it is imperative to develop research focused on studying the phenomenon and its impact with other variables in order to understand its impact on pregnant women. This can help prevent and address negative mental health effects that can affect the functional status and quality of life of pregnant women.

Author Contributions: Conceptualization, K.J., G.I.-P. and M.C.; data curation, K.J.; formal analysis, K.J. and U.C.; funding acquisition, K.J.; investigation, K.J. and M.C.; methodology, K.J., U.C., G.I.-P. and M.C.; project administration, K.J.; supervision, M.C.; writing-original draft, K.J. and U.C.; and writing-review and editing, M.C. and G.I-P. All authors have read and agreed to the published version of the manuscript.

Funding: The research was financed by the funds from the Medical University of Białystok with a grant no. SUB/3/DN/21/008/3310 awarded by the Polish Ministry of Education and Science in the form of a subvention for maintaining and developing research potential in 2021. The APC was funded by Medical University of Białystok.

Institutional Review Board Statement: The study was conducted according to the guidelines of the Declaration of Helsinki, and approved by the Ethics Committee of the Medical University of Białystok, Poland (No. APK.002.248.2021).

Informed Consent Statement: Informed consent was obtained from all the subjects involved in the study.

Data Availability Statement: Data are available upon reasonable request.

Acknowledgments: The authors thank all respondents who participated in the study.

Conflicts of Interest: The authors declare no conflict of interest. The funders had no role in the design of the study; in the collection, analyses, or interpretation of data; in the writing of the manuscript, or in the decision to publish the results.

\section{References}

1. COVID-19 Dashboard by the Center for Systems Science and Engineering (CSSE) at Johns Hopkins University (JHU). Available online: https:/ / gisanddata.maps.arcgis.com/apps/dashboards/bda7594740fd40299423467b48e9ecf6 (accessed on 8 October 2021).

2. Ministerstwo Zdrowia: Mapa Zarażeń Koronawirusem (SARS-CoV-2). Available online: https://www.gov.pl/web/koronawirus/ wykaz-zarazen-koronawirusem-sars-cov-2 (accessed on 8 October 2021).

3. COVID-19 Mental Disorders Collaborators. Global prevalence and burden of depressive and anxiety disorders in 204 countries and territories in 2020 due to the COVID-19 pandemic. Lancet 2021, 398, 1700-1712. [CrossRef]

4. Brooks, S.K.; Webster, R.K.; Smith, L.E.; Woodland, L.; Wessely, S.; Greenberg, N.; Rubin, G.J. The psychological impact of quarantine and how to reduce it: Rapid review of the evidence. Lancet 2020, 395, 912-920. [CrossRef]

5. Witteveen, D.; Velthorst, E. Economic hardship and mental health complaints during COVID-19. Proc. Natl. Acad. Sci. USA 2020, 117, 27277-27284. [CrossRef] [PubMed]

6. Buekens, P.; Alger, J.; Bréart, G.; Cafferata, M.L.; Harville, E.; Tomasso, G. A call for action for COVID-19 surveillance and research during pregnancy. Lancet Glob. Health 2020, 8, e877-e878. [CrossRef] 
7. $\quad$ Luong, T.C.; Pham, T.T.M.; Nguyen, M.H.; Do, A.Q.; Pham, L.V.; Nguyen, H.C.; Nguyen, H.C.; Ha, T.H.; Dao, H.K.; Trinh, M.V.; et al. Fear, anxiety and depression among pregnant women during COVID-19 pandemic: Impacts of healthy eating behaviour and health literacy. Ann. Med. 2021, 53, 2120-2131. [CrossRef] [PubMed]

8. Rashidi Fakari, F.; Simbar, M. Coronavirus Pandemic and Worries during Pregnancy; a Letter to Editor. Arch. Acad. Emerg. Med. 2020, 8, e21.

9. Ayaz, R.; Hocaoğlu, M.; Günay, T.; Yardımcı, O.D.; Turgut, A.; Karateke, A. Anxiety and depression symptoms in the same pregnant women before and during the COVID-19 pandemic. J. Perinat. Med. 2020, 48, 965-970. [CrossRef] [PubMed]

10. Berthelot, N.; Lemieux, R.; Garon-Bissonnette, J.; Drouin-Maziade, C.; Martel, É.; Maziade, M. Uptrend in distress and psychiatric symptomatology in pregnant women during the coronavirus disease 2019 pandemic. Acta Obstet. Gynecol. Scand. 2020, 99, 848-855. [CrossRef]

11. López-Morales, H.; Del Valle, M.V.; Canet-Juric, L.; Andrés, M.L.; Galli, J.I.; Poó, F.; Urquijo, S. Mental health of pregnant women during the COVID-19 pandemic: A longitudinal study. Psychiatry Res. 2021, 295, 113567. [CrossRef]

12. Ravaldi, C.; Wilson, A.; Ricca, V.; Homer, C.; Vannacci, A. Pregnant women voice their concerns and birth expectations during the COVID-19 pandemic in Italy. Women Birth 2021, 34, 335-343. [CrossRef]

13. Eastwood, J.; Ogbo, F.A.; Hendry, A.; Noble, J.; Page, A.; Early Years Research Group (EYRG). The Impact of Antenatal Depression on Perinatal Outcomes in Australian Women. PLoS ONE 2017, 12, e0169907. [CrossRef]

14. Sūdžiūtè, K.; Murauskienè, G.; Jarienè, K.; Jaras, A.; Minkauskienè, M.; Adomaitienè, V.; Nedzelskienè, I. Pre-existingmental health disorders affect pregnancy and neonatal outcomes: A retrospective cohort study. BMC Pregnancy Childbirth 2020, 20, 419. [CrossRef]

15. Wrześniewski, K.; Sosnowski, T.; Matusik, D. Inwentarz Stanu i Cechy Leku STAI. Polska Adaptacja STAI; Pracownia Testów Psychologicznych Polskiego Towarzystwa Psychologicznego: Warsaw, Poland, 2002.

16. Knight, R.G.; Waal-Manning, H.J.; Spears, G.F. Some norms and reliability data for the State-Trait Anxiety Inventory and the Zung Self-Rating Depression scale. Br. J. Clin. Psychol. 1983, 22, 245-249. [CrossRef]

17. Addolorato, G.; Ancona, C.; Capristo, E.; Graziosetto, R.; Di Rienzo, L.; Maurizi, M.; Gasbarrini, G. State and trait anxiety in women affected by allergic and vasomotor rhinitis. J. Psychosom. Res. 1999, 46, 283-289. [CrossRef]

18. Kocjan, J. Short Health Anxiety Inventory (SHAI)-Polish version: Evaluation of psychometric properties and factor structure. Arch. Psychiatry Psychother. 2016, 18, 68-78. [CrossRef]

19. Abramowitz, J.S.; Deacon, B.J.; Valentiner, D.P. The Short Health Anxiety Inventory: Psychometric Properties and Construct Validity in a Non-clinical Sample. Cognit. Ther. Res. 2007, 31, 871-883. [CrossRef]

20. Spitzer, R.L.; Kroenke, K.; Williams, J.B.; Löwe, B. A brief measure for assessing generalized anxiety disorder: The GAD-7. Arch . Intern. Med. 2006, 166, 1092-1097. [CrossRef]

21. Wu, Y.; Zhang, C.; Liu, H.; Duan, C.; Li, C.; Fan, J.; Li, H.; Chen, L.; Xu, H.; Li, X. Perinatal depressive and anxiety symptoms of pregnant women during the coronavirus disease 2019 outbreak in China. Am. J. Obstet. Gynecol. 2020, 223, 240.e1-240.e9. [CrossRef]

22. Banks, J.; Xu, X. The Mental Health Effects of the First Two Months of Lockdown during the COVID-19 Pandemic in the UK. Fisc. Stud. 2020, 41, 685-708. [CrossRef]

23. Vesga-López, O.; Blanco, C.; Keyes, K.; Olfson, M.; Grant, B.F.; Hasin, D.S. Psychiatric disorders in pregnant and postpartum women in the United States. Arch. Gen. Psychiatry 2008, 65, 805-815. [CrossRef]

24. Harville, E.; Xiong, X.; Buekens, P. Disasters and perinatal health: A systematic review. Obstet. Gynecol. Surv. 2010, 65, 713-728. [CrossRef] [PubMed]

25. Yan, H.; Ding, Y.; Guo, W. Mental Health of Pregnant and Postpartum Women during the Coronavirus Disease 2019 Pandemic: A Systematic Review and Meta-Analysis. Front. Psychol. 2020, 11, 617001. [CrossRef] [PubMed]

26. Nowacka, U.; Kozlowski, S.; Januszewski, M.; Sierdzinski, J.; Jakimiuk, A.; Issat, T. COVID-19 Pandemic-Related Anxiety in Pregnant Women. Int. J. Environ. Res. Public Health 2021, 18, 7221. [CrossRef] [PubMed]

27. Bączyk, G.; Cebulska, V.; Kuźlak, V.; Michalak, M.; Bajek, A.; Marcinkowski, J.T. Anxiety levels of pregnant women in pre-delivery period. Probl. Hig. Epidemiol. 2011, 92, 774-777.

28. Mappa, I.; Distefano, F.A.; Rizzo, G. Effects of coronavirus 19 pandemic on maternal anxiety during pregnancy: A prospectic observational study. J. Perinat. Med. 2020, 48, 545-550. [CrossRef]

29. Sinjari, B.; Rexhepi, I.; Santilli, M.; D'Addazio, G.; Chiacchiaretta, P.; Di Carlo, P.; Caputi, S. The Impact of COVID-19 Related Lockdown on Dental Practice in Central Italy-Outcomes of A Survey. Int. J. Environ. Res. Public Health 2020, 17, 5780. [CrossRef]

30. Da Costa, D.; Larouche, J.; Dritsa, M.; Brender, W. Variations in stress levels over the course of pregnancy: Factors associated with elevated hassles, state anxiety and pregnancy-specific stress. J. Psychosom. Res. 1999, 4, 609-621. [CrossRef]

31. Schubert, K.O.; Air, T.; Clark, S.R.; Grzeskowiak, L.E.; Miller, E.; Dekker, G.A.; Baune, B.T.; Clifton, V.L. Trajectories of anxiety and health related quality of life during pregnancy. PLoS ONE 2017, 12, e0181149. [CrossRef]

32. Qiu, J.; Shen, B.; Zhao, M.; Wang, Z.; Xie, B.; Xu, Y. A nationwide survey of psychological distress among Chinese people in the COVID-19 epidemic: Implications and policy recommendations. Gen. Psychiatry 2020, 33, e100213. [CrossRef]

33. Yassa, M.; Yassa, A.; Yirmibeş, C.; Birol, P.; Ünlü, U.; Tekin, A.; Sandal, K.; Mutlu, M.; Çavuşoğlu, G.; Tug, N. Anxiety levels and obsessive compulsion symptoms of pregnant women during the COVID-19 pandemic. Turk. J. Obstet. Gynecol. 2020, 17, 155-160. [CrossRef] 
34. Saccone, G.; Florio, A.; Aiello, F.; Venturella, R.; De Angelis, M.C.; Locci, M.; Bifulco, G.; Zullo, F.; Di Spiezio Sardo, A. Psychological impact of coronavirus disease 2019 in pregnant women. Am. J. Obstet. Gynecol. 2020, 223, 293-295. [CrossRef]

35. Hocaoglu, M.; Ayaz, R.; Gunay, T.; Akin, E.; Turgut, A.; Karateke, A. Anxiety and Post-Traumatic Stress Disorder Symptoms in Pregnant Women during the COVID-19 Pandemic's Delay Phase. Psychiatr. Danub. 2020, 32, 521-526. [CrossRef] 